American Journal of Pharmaceutical Education 2020; 84 (8) Article 8197.

\title{
COMMENTARY
}

\section{COVID-19 Pandemic Challenges and Lessons Learned by Pharmacy Educators Around the Globe}

\author{
Marina Kawaguchi-Suzuki, PharmD, PhD, ${ }^{\text {a,b }}$ Naomi Nagai, $\mathrm{PhD},{ }^{\mathrm{c}}$ \\ Rita Oghenekevwe Akonoghrere, PharmD, MPharm, MPH, ${ }^{\mathrm{d}}{ }^{\mathrm{J}}$ ames A. Desborough, PhD, MPharm ${ }^{\mathrm{e}}$ \\ ${ }^{a}$ Pacific University, Office of Global Pharmacy Education and Research, Hillsboro, Oregon \\ ${ }^{\mathrm{b}}$ Editorial Board Member, American Journal of Pharmaceutical Education, Arlington, Virginia \\ ${ }^{\mathrm{c}}$ Musashino University, Faculty of Pharmacy, Tokyo, Japan \\ ${ }^{\mathrm{d}}$ Delta State University, Faculty of Pharmacy, Abraka, Nigeria \\ ${ }^{\mathrm{e}}$ University of East Anglia, Norwich Research Park, Norwich, United Kingdom
}

Submitted May 29, 2020; accepted June 10, 2020; published August 2020.

The coronavirus identified in 2019 (COVID-19) has affected peoples' lives worldwide. This pandemic forced both pharmacy faculty members and students to adapt to a new teaching and learning environment not only in the United States but around the globe. Pharmacy educators faced challenges and opportunities to convert classroom learning and experiences, as well as student assessments, to a remote or online format. The unique approaches taken to overcome difficulties in various countries showed pharmacy faculty members' resilience in the face of adversity and their determination to continue providing education to students. The pandemic also shed light on areas needing improvement for pharmacy educators to work on in the future.

Keywords: pharmacy, education, COVID-19, SARS-CoV-2, pandemic

Severe acute respiratory syndrome coronavirus 2 (SARS-CoV-2) and the infection caused by the SARSCoV-2, known as COVID-19, influenced peoples' lives worldwide. The World Health Organization declared the COVID-19 outbreak a pandemic on March 11, 2020. Travel restrictions came into effect in various countries. Many cities were put under a stay-at-home order. Because of the international spread of the virus, pharmacy educators faced various challenges, not only in the United States but also in many other countries.

Policies set by each country's government and/or individual universities have affected the entire spectrum of work for pharmacy educators. We showed resilience as we continued providing education to students, conducting research, serving the profession, and taking care of patients. In the United States, a series of webinars were conducted by pharmacy organizations for deans and faculty members to share information and seek solutions to issues raised in the pandemic. A document, "Pharmacists as Front-Line Responders for COVID-19 Patient Care," were put together by the leaders of US pharmacy organizations. ${ }^{1}$ Regardless of our global location, pharmacy

Corresponding Author: Marina Kawaguchi-Suzuki, Pacific University, Office of Global Pharmacy Education and Research, 222 SE 8th Ave., Ste. 451, Hillsboro, OR 97123. Tel: 503-352-2676. Email: marina.suzuki@pacificu.edu educators made efforts by moving teaching platforms online, reformatting their examinations to conduct online assessments, and adjusting the requirements for experiential education. Many pharmacy organizations and universities opened up registration for online continuing education, making it free of charge for pharmacists seeking learning opportunities at home. Schools and colleges of pharmacy compounded hand sanitizers to distribute within their communities, and personal protective equipment was donated from university laboratories to local hospitals and clinics. Science faculty members got involved in research collaborations related to SARS-CoV-2 while practice faculty members expanded their clinical services through telehealth and answered patients' and practitioners' drug information questions on COVID-19. Pharmacy educators not only continued to teach students, but also had a chance to educate the general public on how to prevent the spread of infection. While US pharmacy educators navigated through the major and minor crises the pandemic presented, similar challenges were experienced and overcome around the globe.

\section{Experience in Japan}

The Japanese government declared a nationwide state of emergency in April 2020 and asked citizens to restrict their movement. ${ }^{2}$ The government promoted the 


\section{American Journal of Pharmaceutical Education 2020; 84 (8) Article 8197.}

avoidance of three "C's" (close spaces, crowded places, and close-contact settings). The National Examination of Pharmacists is annually conducted in February to license new pharmacists nationwide, and this examination was not affected. However, the declaration coincided with the start of the academic year, which traditionally begins in April and is completed the following March. Most universities voluntarily closed their campuses and cancelled graduation and entrance ceremonies.

Pharmacy education and research activities were affected because of the limited access to campus for the faculty members and students. Pharmacy schools could not hold lectures on campus in the first half of the 2020 academic year, so pharmacy educators had to work remotely and teach online. ${ }^{3}$ Each pharmacy school established guidelines according to the policies published by the government and the Council on Pharmaceutical Education. ${ }^{4}$ The policy allowed each pharmacy school to flexibly set the start date of their classes in the 2020 academic year by using online and/or on-demand lectures, which were new to many pharmacy schools in Japan. Adjustments were similarly made to training schedules and sites for experiential education. Japanese pharmacy students are traditionally required to complete a thesis for graduation. To accomplish this, the location for their research activities shifted to their home, except for projects requiring hands-on participation in the laboratory for which cautious measures were taken to avoid infection. Clinical research also posed a challenge with restricted access to health care facilities.

The pandemic rapidly advanced the integration of information and communication technology (ICT) in the Japanese education system. Pharmacy educators were asked to take actions based on students' feedback regarding their remote learning experience on an ongoing basis. The continuing adjustments of their teaching methods to accommodate students' situations led to more intensive communication between students and faculty members during the pandemic than ever before. While the use of ICT is promising even after the pandemic is over, student outcomes that still require face-to-face education need to be identified and handled differently than ones that can be achieved through online education. Furthermore, educators expect that certain modifications will be made to pharmacy curriculum in the future, such as the addition of computer science and data science courses to strengthen students' future competency in ICT.

During the pandemic, the government, universities, and industries worked together and created an official framework for facilitating the use of copyrighted materials for educational purposes. They also offered the following to pharmacy students: a tuition waiver or reduction, supplemental financial loans, and subsidies for the purchase of ICT equipment for online classes. ${ }^{2,3}$ To further promote the use of ICT in future education, an initiative was started to standardize the online systems/platforms and devices for remote learning. While the pandemic introduced the new ICT modality and the reform of educational formats, the infrastructure needs to be maintained and promoted with ongoing technical and financial support from the government to provide equal learning opportunities among students.

\section{Experience in Nigeria}

African countries recorded their first case of COVID-19 in Algeria on February 25, 2020. ${ }^{5}$ On February 28, the Federal Ministry of Health announced the first confirmed case in Nigeria. ${ }^{6}$ On March 30, the President of the Federal Republic of Nigeria issued a lockdown prohibiting nonessential activities. The closure of all schools and universities in Nigeria and neighboring African countries was announced at the same time as the lockdown.

With university closures, all didactic classes, hospital rotations (which take place during the final year of the academic program), and cocurricular activities were suspended. However, students were allowed to carry out their off-campus research under a faculty member's remote supervision. Students' participation in internships (a paid work opportunity completed after the academic program and a prerequisite before taking the licensure examination) were not affected by school closures; however, movement restrictions affected some students' ability to resume work. The Pharmacists Council of Nigeria (PCN) continued to run their online training for the Foreign Graduate Orientation Program, which is a program for foreign graduates to be licensed in Nigeria. ${ }^{7}$ However, in Nigeria and neighboring African countries, timely guidance from the accreditation and regulatory agencies was lacking. Hence, a focus group was created by faculty members from different institutions to deliberate on each other's lessons.

The major challenge among the pharmacy educators was their limited capacity for e-learning. A previous study showed most tertiary schools in Nigeria had no provision for remote teaching. ${ }^{8}$ Many pharmacy educators had to face how underequipped pharmacy schools were and how underprepared the faculty members were in responding to situations that would require effective online teaching. However, faculty members became creative by utilizing open resources, social media, and phone apps for the teacher-student interface. While the Federal Ministry of Education advocates e-learning, another challenge was the lack of stability in telecommunication signals in many 


\section{American Journal of Pharmaceutical Education 2020; 84 (8) Article 8197.}

areas, resulting in inability for some students to access the internet. As e-learning cannot replace students' coursework, especially laboratory work, under such circumstances, their study needed to be resumed from where it was suspended after the campus reopened. Through this pandemic, the need for more incorporation of technology into teaching was recognized and embraced. The PCN sees an opportunity for an expansion of their accreditation criteria to include facilities for remote learning for students in case of similar circumstances in the future.

Another lesson learned in the pandemic was the need for recognition of pharmacists as frontline workers in their role of mitigating the impact of global pandemics in resource limited countries in Africa. To achieve this, volunteering opportunities need to be expanded for pharmacy students, so that students will be prepared as frontline workers for another emergency. The review of pharmacy curriculum was put under consideration to include laboratory work in virology and service work, focusing on public health, to enable students to handle another pandemic in the future.

The reflection among pharmacy educators in Nigeria and surrounding African countries was the need for standardized national policy or framework from the accreditation bodies and Ministries of Education to guide pharmacy education in emergency situations that destabilize routine classroom learning. Pharmacy educators in Africa acknowledged the need for the educational system to become more willing and capable of change for the future.

\section{Experience in the United Kingdom}

The first significant impacts of the pandemic on pharmacy education in the United Kingdom started in early March 2020 as some international students requested to return home. By March 13, many higher educational institutions ceased face-to-face teaching, with official government notice to close schools and colleges by March 20 and the UK entering an official lockdown on March 23. 9,10

The traditional model for pharmacy education is a four-year academic program followed by a separate 52week training period with a registered employer, known as the preregistration year. ${ }^{11}$ Pharmacy training in the United Kingdom uses one high-stakes summative assessment at the end of the preregistration year as the final decision on pharmacist's licensure. Thus, the greatest challenge faced in pharmacy education was with preregistration students and their cancelled registration assessment. The General Pharmaceutical Council announced to develop a provisional registration option until preregistration students can sit for the assessment. ${ }^{12}$ Pharmacy students in the academic program were given the opportunity to be deployed to support the pharmacy workforce on a greater scale than usual as the pharmacy profession in all sectors was under pressure in the pandemic. ${ }^{13}$ Depending on the student's competency, this ranged from delivering medicines, to providing advice, to dispensing medicine under supervision.

The COVID-19 pandemic forced pharmacy educators to stop and think about what they were doing and how they were doing it. Pharmacy faculty members and students had to learn how to use technology and adjust their delivery and interaction. Asynchronous teaching had not previously been the standard at many UK institutions but was quickly adopted by pharmacy educators to improve the accessibility of teaching and learning during the pandemic. The move towards flipped teaching was noted, and recitation classes were also delivered effectively online, using breakout rooms and the ability to share and work on documents together. ${ }^{14}$ However, an effective online solution to skill-based courses has not been extensively tested. For assessments, the decision-making principle in moving online was student welfare and fairness. The implemented strategies included to grant extensions and reassessments to students without penalty on their final grades. Traditional written examinations were amended to open-book assessments with extended time given for completion. ${ }^{14,15}$ While these strategies were valid and fair, their reliability needs to be confirmed.

The COVID-19 pandemic has enabled pharmacy educators to reflect on their teaching and assessment like never before. It has driven innovation and change, and turned the classroom back into a continuous experiment. The students' management of online education appears to facilitate self-directed learning and thus develops a set of key transferable skills. In the UK, it is hoped the pandemic will also help the whole pharmacy profession appreciate the value of their student body and create a culture where developing the future workforce is central to everyone's role. Thus, preceptors would be empowered to individually assess student competence and provide supervision and work experience appropriate to each student. This pandemic may also provide the impetus to review the preregistration training and design a sign-off process that is not so reliant on one final written assessment for registration. These potential changes can make the registration process for pharmacists more sustainable, fair, valid, and reliable for any future uncertainty the United Kingdom faces.

\section{CONCLUSION}

As each country gradually recovers from the COVID19 pandemic, pharmacy educators are encouraged to consider the positive impacts we can continue to make to our students and to our profession. The strengthened areas by this pandemic likely include: online teaching and learning, research/practice collaborations for remote 


\section{American Journal of Pharmaceutical Education 2020; 84 (8) Article 8197.}

activities, and expansion of pharmacists' and students' clinical services, such as telehealth. The potential outcomes of measures taken during the pandemic, eg. changes to the training curriculum, students' future performance in licensure examinations, and their practice performance at their place of employment, are also of interest. Moreover, this might be a good time to reevaluate the overall impact of pharmacy students' contribution to patient care, as well as the public's understanding of the pharmacy profession. Despite all the travel restrictions, lockdowns, and social distancing, this pandemic has actually brought all pharmacy educators together and will make our profession stronger around the globe.

\section{ACKNOWLEDGMENTS}

We acknowledge the following colleagues for the preparation and review of this commentary: Kiyoshi Mihara, $\mathrm{PhD}$ (Musashino University, Japan), Kou Hiroya $\mathrm{PhD}$ (Musashino University, Japan), Toshiaki Katada, $\mathrm{PhD}$ (Musashino University, Japan), Ray I. Ozolua, B.Pharm, M.Sc, $\mathrm{PhD}$ (University of Benin, Nigeria), Arinola Joda, B.Pharm, PharmD, MPharm, PhD (University of Lagos, Nigeria), Ubaka Chukwuemeka, B.Pharm, PhD (University of Nigeria Nsukka, Nigeria), Mohammed Garba Magaji, B.Pharm, M.Sc, PhD (Ahmadu Bello University, Nigeria), Yinka James Oyeniyi, B.Pharm, Msc, PhD (Usmanu Danfodiyo University, Nigeria), Sa'ad Abdullahi, B.Pharm, MSc, $\mathrm{PhD}$ (University of Ilorin, Nigeria), Akinniyi Aje, B.Pharm, MPharm, PharmD (University of Ibadan, Nigeria), Gideon O. Okpanachi, B.Pharm, MSc, PhD (Gombe State University, Nigeria), Ezekiel Olugbenga Akinkunmi, B.Pharm, MSc, PharmD, PhD (Obafemi Awolowo University, Nigeria), Omolola Fatokun; B.Pharm, MSc (National Institute for Pharmaceutical Research and Development, Nigeria), Kenneth Okolo Obinna, B.Pharm, MBA, BSc, $\mathrm{PhD}$ (Enugu State University of Science and Technology, Nigeria), Amaka A. Mgbahurike, BPharm, M.Sc, PharmD, $\mathrm{PhD}$ (University of Port Harcourt, Nigeria), and Charles Ansah, B.Pharm, MSc, DIC, PhD (Kwame Nkrumah University of Science and Technology Kumasi, Ghana).

\section{REFERENCES}

1. APhA, ASHP, NASPA, et al. Pharmacists as Front-Line Responders for COVID-19 Patient Care. https:// www.pharmacist.com/sites/default/files/files/APHA\%20Meeting\% 20Update/PHARMACISTS_COVID19-Final-3-20-20.pdf.

Published 2020. Accessed August 11, 2020.

2. Ministry of Health, Labour and Welfare. https://www.mhlw.go.jp/ index.html. Accessed August 11, 2020.

3. Ministry of Education, Culture, Sports, Science and Technology. [COVID-19] Information about MEXT's measures. https:// www.mext.go.jp/en/about/index.htm. Accessed August 11, 2020. 4. Council on Pharmaceutical Education. https://yaku-kyou.org/. Accessed August 11, 2020.

5. World Health Organization. Situation Reports on COVID-19 Outbreaks, WHO AFRO Region. https://www.afro.who.int/healthtopics/coronavirus-covid-19. Published 2020. Accessed August 11, 2020.

6. Nigeria Centre for Disease Control. COVID-19 Nigeria. https:// covid19.ncdc.gov.ng/. Published 2020. Accessed August 11, 2020. 7. Pharmacists Council of Nigeria. Education \& Training. http:// www.pcn.gov.ng/index.php. Published 2020. Accessed August 11, 2020 .

8. Nwagwu WE. E-learning readiness of universities in Nigeria-what are the opinions of the academic staff of Nigeria's premier university? Education and Information Technologies. 2020;25:1343-1370.

9. PM address to the nation on coronavirus: 23 March 2020 [press release]. London: UK Government 2020.

10. Schools, colleges and early years settings to close [press release]. London: Department for Education 2020.

11. General Pharmaceutical Council. Future Pharmacists: Standards for the Initial Education and Training of Pharmacist. London, UK. 2011.

12. Pharmacist pre-registration training update [press release]. London: General Pharmaceutical Council 2020.

13. Health Education England, NHS Education for Scotland, Health Education and Improvement Wales, Pharmacy Schools Council, Royal Pharmaceutical Society, British Pharmaceutical Students' Association. Joint Guidance: Facilitating deployment of pharmacy undergraduate students to support the pharmacy workforce. 2020. 14. British Pharmacological Society Education and Training Committee. Universities responses to suspension of face to face teaching. British Pharmacological Society; March 30, 2020. 15. Health Education England, Health Education and Improvement Wales, NHS Education for Scotland. Supporting the COVID-19 response: Guidance for Pre-registration Trainee Pharmacists and Pre-registration Trainee Pharmacy Technicians. 2020. 